\title{
New reports from the NIOSH health hazard evaluation program
}

\author{
Evaluation of Occupational Exposures at an Electronic \\ Scrap Recycling Facility \\ Diana Ceballos, Lilia Chen, Elena Page, Alan Echt, \\ Aalok Oza, Jessica Ramsey
}

The Health Hazard Evaluation Program received a request from a health and safety manager at an electronic scrap recycling facility. The employer was concerned about workplace exposures, including lead and cadmium. Computers, monitors, hard drives, televisions, printers, light bulbs, and other e-scrap were recycled and processed at this facility. The recycling operations included cathode ray tube (CRT) processing (demanufacturing and glass breaking operations), and electronic sorting, demanufacturing, shredding, and bailing operations for all other electronics. We made multiple visits between 2012 and 2013 to evaluate employee exposures to workplace contaminants. We collected air samples for metals, dust, and crystalline silica; surface wipe samples for metals; and blood and urine samples for metals. We also did employee medical interviews; reviewed the facility's health and safety monitoring plans; and evaluated noise, engineering controls, and ergonomics in the work areas. We measured an overexposure to lead during shredder sorting and overexposures to cadmium on two employees during CRT buffing and grinding. We measured overexposures to noise on employees during CRT buffing and grinding, shredder sorting, forklift driving, and baling. We found metal contamination on surfaces throughout the facility; potentially contaminated air was recirculated back into the production area. We found lead on the clothing and skin of employees and on work surfaces. Blood lead levels ranged up to 13.7 micrograms per deciliter of blood. Two employees were above 10; a level of 10 or above is considered elevated. We noted the potential for taking lead and other contaminants outside of the workplace. Employees were exposed to ergonomic risk factors including extreme working postures, forceful exertions, and repetitive motions. Our recommendations to the employer included (1) following the OSHA lead and cadmium standards, (2) starting a medical monitoring program for all employees exposed to lead, (3) starting a hearing conservation program, (4) requiring respirator use in
CRT buffing and grinding and shredder operations, (5) using wet methods or a vacuum with a high efficiency air filter instead of sweeping, and (6) designing work tasks and workstations to reduce bending, lifting, and other postures that do not allow employees to work efficiently and comfortably. We recommended the employees (1) provide and discuss this report with their doctor and discuss blood lead tests for their children and other family members, (2) wear required personal protective equipment, and (3) take a shower at the end of the shift and avoid wearing work clothing or shoes home. A full report is available at http://www.cdc.gov/niosh/hhe/ reports/pdfs/2012-0100-3217.pdf.

\section{Lead Exposure at a Firing Range and Gun Store Elena Page, Catherine Beaucham, Mark Methner}

The Health Hazard Evaluation Program received a request for an evaluation from employees of a firing range and gun store. Employees were concerned about lead exposure and reported being diagnosed with lead poisoning and being medically removed from the workplace by an occupational physician. We visited the facility in December 2013 to interview employees, assess lead exposures, and evaluate ventilation system performance. In February 2014, we provided a summary of the environmental sampling results to the employer and employee representatives and personal sampling results were sent to each employee who participated in the evaluation. Employees generally spent most of their work day at the sales counter in the showroom or in the office. They occasionally entered the ranges to assist shooters who were experiencing difficulty or to supervise league shooting. On Saturdays, employees performed a deep cleaning of the firing ranges. Each range had a separate single-pass ventilation system that supplied outside air to the range and exhausted the air directly outdoors without recirculation. The areas of the facility other than the range were served by two recirculation ventilation systems. All employees had elevated blood lead levels, defined as greater than or equal to $10 \mu \mathrm{g} / \mathrm{dL}$, when tested by the employer in November 2013. Employee BLLs ranged from 19.9-40.7 $\mu \mathrm{g} / \mathrm{dL}$. No employees had undergone the medical surveillance 
required by $\mathrm{Cal} / \mathrm{OSHA}$. Air sampling results for lead were below the Cal/OSHA permissible exposure limit of $50 \mu \mathrm{g} / \mathrm{m}^{3}$. We found lead on all tested surfaces in the range and in the showroom. Employees also had lead on their hands and shoes as they left work to go home. The ventilation system had numerous deficiencies, and lead contaminated air circulated throughout the building. Multiple openings between the ranges and the wall separating them from the showroom allowed lead dust to migrate to the air handling units that serve the showroom and office/classroom area. We recommended the employer (1) switch to lead-free ammunition, (2) remove all employees with blood lead levels of $20 \mu \mathrm{g} / \mathrm{dL}$ or higher from exposure to lead until their two blood lead levels taken a month apart drop below $15 \mu \mathrm{g} / \mathrm{dL}$, (3) hire a ventilation engineer to modify or redesign the ventilation systems, (4) remove lead contamination from the showroom, and (5) follow the Cal/OSHA medical surveillance requirements. We recommended employees (1) talk to their doctor about their exposure to lead at work, (2) not eat, drink, or smoke inside the facility, (3) wash their hands with a lead-removing soap before leaving the facility, and (4) change their clothes and shoes before leaving work to decrease the amount of lead transferred to their car or home. A full report is available at http://www.cdc.gov/niosh/hhe/reports/pdfs/ 2013-0119-3219.pdf.

\section{Evaluation of Erionite and Silica Exposure During Dirt Road Maintenance}

Catherine Beaucham, Marin Harper, Bradley King

The Health Hazard Evaluation Program received a request from a management representative at a federal government agency concerned about potential employee exposures to erionite mineral fibers when maintaining dirt roads in areas where erionite was confirmed or was suspected to be present. We visited two field offices to assess potential employee exposures to erionite and respirable crystalline silica (quartz) during road maintenance activities in October 2012 and August 2013. Erionite is a naturally occurring mineral found in fine-grained sediments such as volcanic ash deposits that have been altered by weathering and ground water. Erionite deposits have been identified in all of the western states except Washington. We observed employees blading and grading dirt roads, replacing culverts and cattle guards, replacing aggregate on parking lots, and pulverizing and analyzing rock samples. We took air samples for mineral fibers and crystalline silica and bulk rock and soil samples to analyze for erionite. We found that employees doing road maintenance activities could be exposed to quartz above the recommended limits. Area air samples indicated a high percentage of quartz, up to $100 \%$. Zeolite mineral fibers, a class of fibers that includes erionite, were not found in the personal air samples. None of the bulk rock samples collected in the areas surrounding where employees worked contained erionite. Because of the variable environmental and geological conditions encountered by the employees and the variability in job tasks, including tasks that aerosolize dust particles, the potential for exposure to erionite and silica dust exists. Therefore, minimizing dust exposure during dust-generating activities is prudent. To address the potential for exposure to dust that may contain erionite or crystalline silica, we recommended the employer (1) not use aggregate that contains erionite to repair roads, (2) maintain air filters in the equipment regularly, (3) wet the soil before doing road maintenance, (4) schedule dust-generating tasks on days when the soil is moist, and (5) provide employees with clothes that are solely designated for work activities. We also recommended monitoring employees' exposure to respirable crystalline silica, and training employees in proper work practices for working in areas that contain crystalline silica or erionite. We recommended employees keep the windows and doors on equipment closed, and not bring work clothing home. A full report is available at http://www.cdc.gov/niosh/hhe/reports/pdfs/2012-0 141-3220.pdf.

Evaluation of Ergonomic Risk Factors, Thermal Exposures, and Job Stress at an Airline Catering Facility Jessica Ramsey, Kristin Musolin, Diana Ceballos, Douglas M. Wiegand, Kenneth Mead

The Health Hazard Evaluation Program received a request from a union representing airline catering employees at one facility. The union was concerned about work-related musculoskeletal disorders (MSDs), extreme hot and cold temperatures, job stress, and employees being injured while working in the kitchen and on the loading docks. At the time of our visit, the facility had approximately 500 employees and operated two shifts. The company catered for one major airline and serviced 16 international flights and 220-260 domestic flights per day. Employees prepared food, beverages, and nonfood amenities. During our evaluation we (1) observed job tasks to see if they posed a risk for work-related MSDs, (2) measured workstation heights and reach distances to determine work-related MSD risk, (3) looked at OSHA logs of work-related injuries and illnesses, (4) measured air temperature and air flow inside cold rooms, and carbon monoxide concentrations at loading docks, and (5) interviewed employees about their work, medical history, health symptoms, job stress, personal protective equipment use, and health and safety concerns. We found that employees were exposed to a combination of risk factors for work-related MSDs 
including awkward postures, forceful exertions, and repetitive motions. The most common injuries reported on the logs were musculoskeletal strain, sprain, or pain. Air temperature inside the food prep cold room averaged $43.1^{\circ} \mathrm{F}$ and $40.8^{\circ} \mathrm{F}$ in the international cold food room. Average air velocities were less than the cold stress ACGIH TLV of 200 feet per minute, thereby reducing the potential cooling effect of air movement. The potential exists for autoclave operators and delivery truck drivers to work in hot conditions during the summer months. No confined space entry procedures were in place for cleaning the autoclave. Employees reported health concerns from hot and cold temperatures, diesel exhaust entering the loading docks during winter days, and reported time pressure, high workload, and lack of social support. To address the risk for work-related MSDs, we recommended redesigning work stations, providing work tables with adjustable heights, rotating employees to different job tasks after every break, and educating employees on MSDs and ergonomics. For cold rooms we recommended installing horizontal baffle deflectors on all refrigerator fans, and providing employees alternative gloves and warm water or dry air heaters to warm their hands. To address the potential for heat stress, we recommended the employer (1) develop and implement a heat stress prevention program, (2) establish mandatory breaks for employees exposed to heat, and (3) ensure new trucks have air conditioning. We also recommended the employer (1) develop a written autoclave cleaning procedure addressing confined space, lockout/tagout, and personal protective equipment; (2) train employees on the health effects of exposure to cold and hot temperatures; (3) present all information to employees in a manner that they can understand; (4) seal loading docks so diesel truck exhaust does not enter the building; and (5) explore and address issues of job stress. A full report is available at http://www.cdc.gov/niosh/hhe/reports/ pdfs/2011-0131-3221.pdf.

\section{Evaluation of Ergonomic Hazards at a Label Manufacturing Facility \\ Jessica Ramsey, Judith Eisenberg}

The Health Hazard Evaluation Program received a request from managers at a label manufacturing facility. The employer was concerned about the potential for musculoskeletal disorders among employees working in the film and paper finishing departments. These employees received large film and adhesive rolls, which they joined through a fully automated system, and then cut the resulting product to size as specified by the purchaser. Finished rolls were transferred from a horizontal conveyor onto a wooden pallet for shipping. In May 2012, we looked at job tasks to find risk factors for work-related musculoskeletal disorders, and spoke with a sample of employees about work, medical history, health symptoms, and health and safety concerns. Our observations indicate that workstations at this facility were not designed so that most people could safely perform job tasks. Employees were working in awkward postures that put them at risk for developing work-related musculoskeletal disorders. Specifically, hand working heights were too low or too high, reach distances were too long, and employees had to continually bend at the waist. Employee reports of back pain were consistent with the ergonomic findings. Lack of a formal training program on job tasks resulted in a workforce that had inconsistent knowledge of how to do its job safely. Some employees were required to work long hours, which put them at an increased risk of injury because of lack of adequate recovery time. To reduce the potential for musculoskeletal disorders, we recommended the employer (1) design work areas to have a working height of 27 to 62 inches, (2) provide adjustable height work tables, (3) educate employees about musculoskeletal disorders and ergonomic hazards, (4) reduce mandatory overtime hours, (5) implement a training program to show all new employees how to do their job tasks safely, and (6) cross-train employees for multiple job tasks to increase the number of employees who can cover additional shifts. We recommended employees use a pallet lift, two-person lifting, or sliding techniques when handling pallets, avoid working below the knees and above the shoulders or reaching across pallets or conveyor belts, take part in safety and ergonomic committees, and report symptoms and injuries to supervisors and medical staff as soon as they happen. A full report is available at http://www.cdc.gov/niosh/hhe/reports/pdfs/2012-0 121-3225.pdf. 